\title{
KNOWLEDGE SHARING SYSTEMS AND CULTURAL IDENTITY IN ORGANIZATIONS
}

\author{
Shana M. D'Aurora, Steubenville City Schools, sdaurora@scsohio.org \\ Scott C. Spangler, Robert Morris University, scsst295@mail.rmu.edu \\ ChristopherA.Wydra, Robert Morris University, cawst157@mail.rmu.edu
}

\begin{abstract}
Purpose - Knowledge is only as good as its transfer mechanism. Physiological roadblocks can inhibit knowledge or information transfer flow between the sexes. Through today's (2014) streaming information technology systems, knowledge is shared in an open arbitrary methodology. Communicator's tend to blame the audience for not accepting a message, but it is often that the sender, encoding process or channels chosen were not applied correctly. Everything is systematic and structured for efficiency of use, but not comprehension. This paper will seek to understand knowledge transfer "noises" and comprehension disengagements in organizational tacit or silent knowledge transfers.
\end{abstract}

Keywords: Information Technology (IT), Ethics, IT and Ethics

\section{INTRODUCTION}

In the first part of the last century, organizational theory focused on the particular tasks and actions each industrial worker was supposed to undertake in order to produce goods and services as effectively as possible [40]). In the second half of the last century, it was no longer just the detailed task performance, but the whole interrelated system of tasks and roles that were in focus [28]. From the beginning of the 1980s values and beliefs, also called organizational culture, began to become a subject of study [27]

Tacit knowledge is identified in two forms: proximal and distal. The coherence, meaning, or value of the message in the "first to the second" attendance determines the receiver's abilities to interiorize the messages function, or awareness comprehensions in the meanings from the sender or "entity" [32] Explicit knowledge can be transferred in a "formal language, including grammatical statements, mathematical expression and specification manuals, and can be transmitted across individuals, formally and easily" [11]. Tacit knowledge is hard to formulate into written language, and is gained through individual experiences and belief structures [32].

From the middle of the 1990s, the notion of virtual organization became more and more in focus due to the fast increasing dissemination and implementation of information and communication technologies (ICT) and the increasing globalization of the World Economy [8]. Virtual organizations and virtual teams have become more prominent in the workforce. Virtual teams are rarely in the office, and monitoring work abilities and accountability becomes more difficult [26]. Thus, during the last century, we have witnessed a steady expansion in the scope of the human aspects that are supposed to be subject to management and control: “...The extension of control was from the actions of a human person at work, to the relationships between human persons, to the beliefs and values of human persons and then to the very mind of human persons" [40].

Venkitachalam, \& Busch, (2012) [43], Beginning with the philosophical groundwork of tacit knowledge, there are studies that examined the meaning and definition of tacit knowledge and few studies have investigated analyzing tacit knowledge. The question of whether tacit knowledge may be codified is one that requires further clarification. In the current literature with reference to "knowledge", scholars have defined different types of knowledge such as procedural and declarative to name a few; so the critical inquiry to undertake is on the categories of "tacit knowledge" and the potential areas to explore are:

- If tacit knowledge can be articulated, how often can such knowledge still be considered as "tacit"?

- Do different types of tacit knowledge exist?

- To what extent can tacit knowledge be articulated? 


\section{Understanding the communication model}

Anyone who has observed a group of people discussing a topic has observed that not everyone in the group spends the same amount of time talking. Information flows according to status or power. In general, persons with high status or actual or perceived power send and receive more messages than do other members of the group (Collins \& Guetzkow, 1964).

Signal meanings and associations in information may become lost or disorientated in its presentation through a transfer mechanism. Shannon and Weaver's (1949) transmission model suggested a simplistic methodology of information flow. A sender transmits a message to a receiver on the other side of the communication chain or channel. The linkage is concerned with reception and not interpretation. The model was originally developed to explain electronic transmission of data; the Shannon Weaver model has been well used because of its simplicity and its foundation in scientific principle [5] The message interpretation may become disorientated through transmission's noise or the receiver's translation interpretations. The model, which is only concerned with the transmission channel, doesn't regard the effectiveness of the translation by the receiver. In organizations, the message effectiveness is directly related to the receiver's ability to translate the explicit or tacit knowledge [5].

Knowledge can come in many forms through the transmission. The messages can be simple words, signs, or symbols that convey a message to the receiver. Scholars have debated the amount of information we can transmit in tacit knowledge, unless there is an intensive period of understudy. Polanyi contends, "We know more than we can tell" in the messaging. The from-to, a sender to a receiver structure, which is limited to indwelling perceptions, is an accumulation of the formalized understandings in the present tense [32].

Tacit knowing as defined by Ikujiro Nonaka: "deeply rooted in action and in an individual's commitment to a specific context- a craft or profession, a particular technology or product market, or the activities of a work group or team. Nonaka, also explains tacit knowing as "consisting partly of technical skills- the kind of informal, hard to pin down skills captured in the term "know-how" [25] Explicit knowing as defined by Nonaka: the end point of innovation is the explicit knowing. When companies begin production that is the end point of the transition of the beginning stages of tacit knowing into the formal and systematic explicit knowing, explicit knowing is easily communicated and shared [25]

Explicit knowledge comes from the architecture of shaping tacit experiences into interiorized meanings. The meanings themselves, through the transmissions process, accumulate a redundancy, or sometimes a missing "kinesics" value [2]. The receiver's epistemological values can laden the message with eidos cultural structure noise. The problem with Shannon and Weaver's communication model then lies in the standardization of personality or the scope of inquiry. The scholars' model failed to recognize or care about the channel's reception and acculturation differences in the sender and receiver, which creates the noise before information is received [2].

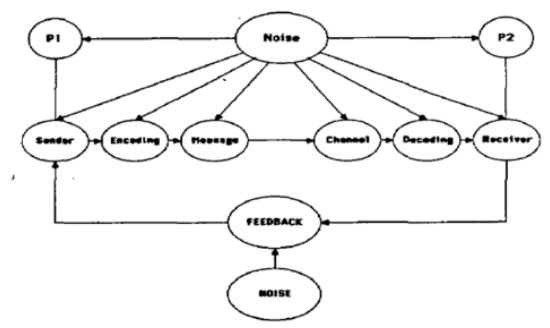

Figure 1. The Transimission Communicaiton Model

The channel capacity paradigm focuses on semantic reaction aspects and arguments about the effectiveness of the receiver's abilities to circumnavigate around external influences in the environment [5]. The communication reaction paradigm shifted attention and focus onto the meaning exchange in information. The paradigm launched a 


\section{Issues in Information Systems \\ Volume 15, Issue I, pp. 248-256, 2014}

focus on encoding and decoding effectiveness in the transmission of knowledge of information, and not just its communication reception. This theory postulates that there is a continuous "loop" or transfer of knowledge between the sender and receiver in the communication process that establishes a larger link to understanding [5].

Wilbur Schramm (1955) introduced a model that illustrated the importance of interpersonal communication. Schramm believed that communication meets the criteria below:

- Communication is something people do

- There is no meaning in a message except what people put into it

- To understand human communication process, one must understand how people relate to each other

In the first stage of Schramm's model, a source sends a message through an encoder; the message is received by a decoder and transmitted to its designation. The source is the mind of the person starting the communication process. The encoder is the process by which ideas are converted to symbols for transmission to another person. The decoder is the process by which symbols are received and converted into ideas by the person receiving the information. The signal is symbols that are produced and transmitted [36]

Modifications:

- Added to the model the context of the relationship, and how that relationship will affect Communicator A and Communicator B.

- Included the social environment in the model, noting that it will influence the frame of reference of both Communicator A and B.

Figure 2, shows Schramm's model of communication, which includes the source which is also known as the encoder, the message or the signal, and the destination which is also recognized as the decoder. The model addresses the sociological aspects involved in communication. Communication or commonness can take place if the fields of the source and destination overlap as shown in the figure below as the field of experience [36]

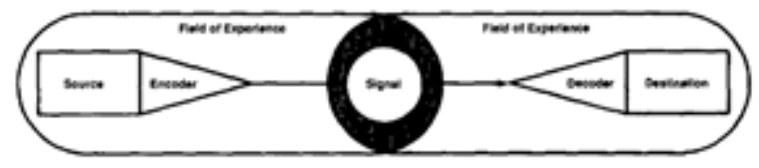

Figure 2: Schramm's Model of Communication

Schramm's contribution to communications theory included the concept that each person has a field of experience that controls both the encoding and decoding of information and determines the meaning of this information. Communication is viewed as an interaction in which both parties actively encode, interpret, decode, transmit, and receive signals. This model includes the feedback of continuously shared information [36].

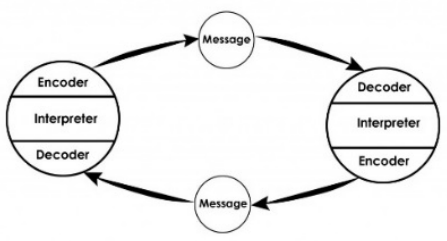

Figure 3: Schramm's Final Model

Signal Available Relevant Accessible (SARA) theory of signaling contends that receivers search through text or messages to prescribe a meaning to the transmissions and decode it according to their environments and cognitive perceptions. The decoding process takes on multiple representation layers in the decoding process that helps establish a memory link to the information. Individual receivers' shared experiences and personal interactions with the bits of tacit knowledge exchanges or transmission enable a value exchange in the information (Shelby, Mazzuchi, \& Sarkani, 2013, p. 116). The scholars found that males and females both retain knowledge and information faster in closed knowledge based training atmospheres, such as computer training sessions compared to 
open collaborative adventures. The scholars' model focuses on understanding that knowledge transfer containing six fields:

(1) "Knowledge is a human act".

(2) "Knowledge is the residue of thinking".

(3) "Knowledge is created in the present moment".

(4) "Knowledge belongs to communities".

(5) "Knowledge circulates through communities in many ways".

(6) "New knowledge is created at the boundaries of old." (p. 118).

The system focuses on a cognitive collaborative model for task specific tacit knowledge transfer. The model follows the Nonaka and Takeuchi's Socialization, Externalization, Combination and Internalization knowledge creation model. The model considers both tacit and explicit knowledge. In the socialization realm, tacit knowledge is to tacit knowledge. Externalization mechanism tacit is converted to explicit, and then combines to explicit to explicit knowledge transfer. The transfer then ends at an internalization realm of explicit knowledge, transferring back into tacit knowledge [24].

\section{Tacit knowledge exchange}

Knowledge alone cannot be explicit in nature. There must be a social context for knowledge to become information. This information is best utilized, learned, and shared in social dynamic contexts. Alexander Graham Bell abandoned training and explicit training, while promoting his telephone invention. Bell created a tacit knowledge exchange through social learning realms. Bell, to facilitate a need and create a social training methodology for the new innovation, placed telephones at lunch counters. By placing the innovations in the social realm, tacit knowledge about utilizing the innovation was shared. Lunch counter customers watched trained users manipulate the innovation. The tacit knowledge sharing method created a "cascade into society" and a social context for "collective knowledge exchanges" neutral of gender [41].

No matter the gender or organizational context, learning is "demand driven." Knowledge is rejected when there is no social need. Organizations provide resources to its members the same as social groups do in order to learn, grow, shape, and foster or facilitate integration. Communities of practice are the methodologies in which individuals structure their identities, and "assimilates knowledge and information" [41]. The message or information is only a driver in context for informing a human framework and behavioral response to the knowledge. The social influences in the channels complicate the messages meanings to the receivers no matter the gender or organizational context [5]. Other human factors implicate messages and the transfer of knowledge. In addition to information and knowledge directly connected to some aspect of work processes or practices is person-related information and knowledge, and this kind of knowledge relates to the behaviors, skills, and attitudes of colleagues and managers that indirectly influence informal learning [4].

Nonaka describes the fundamental approaches to the Japanese business culture as the recognition of creating new knowledge. The creating of new knowledge is done by "tapping the tacit and often highly subjective insights, intuitions, and hunches of individual employees and making those insights available for testing and use by the company as a whole" [25] Nonaka then further details that the successful transition of tacit knowing to explicit knowing as the personal commitment of the company's employees as well as the employee's personal identity within the company.

To understand and analyze the use of tacit knowing in the context of organizational learning, Johnson (2007) suggests a model that explains the mechanisms of learning in organizations. The individual approach to learning through pattern recognition and synthesis supports macro level processes of interpreting, intuiting, integrating and institutionalizing first suggested by Crossan et al. (1999) [9]. Recognizing patterns by filtering out irrelevant ones (that are determined through purposeful exploration (March, 1991)) as well as synthesizing new patterns are then communicated to other staff in the organization, which informs organizational learning and knowledge creation.

Mulder and Whiteley (2007)[23] suggested tacit knowledge could be captured as narrative within three settings; the teleological motive which determine the purpose of capture, the bounded environment where the business operates 


\section{Issues in Information Systems \\ Volume 15, Issue I, pp. 248-256, 2014}

to support corporate objectives and lastly its drivers and controlled vocabulary that is familiar to respondents in their business context.

Despite distinctions in approaches to knowledge management strategy in the existing literature, it is often worthwhile to recognize the relationship that exists between tacit knowledge and explicit knowledge. In this regard, Smith (2001) suggests, "comparing tacit and explicit types of knowledge is a way to think and not point out differences". This means that explicit knowledge signifies the "process" that deals with how knowledge is organized, whereas tacit knowledge represents "practice" that refers to how work is done [35].

\section{Knowledge exchange distortions}

Distortion enters the communication process in the channels. The errors generated depend on the individual's semantic interpretations and or the organization's context [5]. Because organizational tacit and explicit knowledge sharing is primarily a social process, organizations that have the ability to "codify tacit knowledge" create a competitive edge. Knowledge hording centralizes communication and controls power in organizations. Cultural differences and gender differences also create impacting distortions in the information flow. Organizations' managers do not share knowledge because it maintains a measure of control, authority, and power [7]. Interpersonal and social interactions are key directives in social exchanges of an organization's knowledge transfer. Social capital exchanges create bonds and relationship ties between co-workers. Organization networks or clicks like the "Goodold-boys clubs" stymies knowledge transfer. These networks are based on trust, closeness, and friendships" to foster information exchanges and material resources in organizations to promote career advances [11].

Individuals choose memberships in the various organizational networks, and choose whom to exclude form the networks, based on career enhancements and friendships. Formal and informal networks foster tacit and explicit knowledge exchanges. The networks are often grouped as social elements in the business contexts. Senior women in an organization's hierarchical matrix, according to Durbin's 2011 study, will not use their "roles" as a "means of challenge" to break down gender structured networks that stymies knowledge flow and segregation (p. 95).

Senior female executives fail to recognize or refuse to recognize closed or informal networks in organizations. In addition, "heterogeneity" in network compositions creates an exclusion constraint that limits access and reinforces the "gender paradigm" [11]. This paradigm creates another shift towards females "seeking refuge" and allies in only other female organizational members. This network can overcome "isolation" and counter old boy's networks, and create positive in-member benefits that eliminate discrimination (pp. 99-101). Although, knowledge transfer is still contained between two groups that hoard information and fail to cross-culturally connect tacit and explicit organizational knowledge.

Ikuko Tanaka's [24] example of a bread making machine is an illustration of taking the tacit know to the explicit knowing. Explicit knowing can be easily communicated and shared and are reasons companies are able to grow and prosper. The advantage to Japanese business is that employees who identify themselves as part of the whole are willing to communicate this tacit knowledge in hopes that the business will continue to thrive. This is an opposite way of thinking in many Western companies. Employees generally do not self-identify as part of the whole in companies, therefore, lending themselves to keep their tacit knowing personal.

Western culture employees tend to develop the mental models as described by Nonaka that "profoundly shape how we perceive the world around us" [24]. As a Western culture, employees tend to not self-identify as part of the whole in organizations. Employees typically feel replaceable and paranoid for their jobs, because of this tacit knowing is often left out of discussions and planning meetings almost as though to keep themselves from being replaced for something or someone to come along and take the tacit knowing and replace their jobs.

In Davenport's Working Knowledge article, he begins to uncover the important aspects of knowledge management and working knowledge. Consistent with Nonaka's explanation of tacit and explicit knowing, Davenport explains one of the reasons that knowledge is valuable is that it is closer than data or information to action [10]. Also, as Davenport explains knowledge, "can and should be evaluated by the decisions or actions to which it leads" [10]. Davenport's explanation of knowledge keeps in line with Nonaka's details of tacit knowing to explicit knowing and the transition between the two by one's actions. Davenport and Nonaka describe knowledge and knowing as a 
transition between mental modes and cognitive dimensions to the action of articulating information and processes so that individuals may carry out and perform this knowing or action.

Polanyi's description of tacit knowledge or tacit knowing in The Tacit Dimension, Polanyi uses the example of electric shock syllabus and waves as a way to show the connection between tacit and explicit knowing. As Polanyi observes in experiments, "the basic structure of tacit knowing, it always involves two things, or two kinds of things" [30]. For Polanyi and the experiment, the subject was able to connect their tacit knowing of being shocked to the tacit knowing that the shock syllabus would cause a shock feeling to come over them. The subject was able to connect the two instances and make the connection between their own tacit knowing and connect that knowing to the feeling of being shocked. Further, in Polanyi's readings, he summarizes the following actions as, "the functional relation between the two terms of tacit knowing: we know the first term only be relying on our awareness of it for attending to the second" [30].

\section{Socialistic indwelling of cultural identity}

The comprehensive relationship between knowing and understanding an individual's matrix or cultural sphere becomes a spiral loop of tacit dimensions formed through indwelling experiences. The tacit attention of attending, while indwelling forms the functional awareness of meaning. The origin of knowledge category encompasses those conceptions of tacit knowledge that emphasize the factors, events, and developments by which a person knows or can do some things [42].

Once awareness of meaning is perceived semi- cognitively, we deconstruct it through the spiral process, or attempts to create comprehension itself. Through the deconstructive analysis, explicit relationships are conceived sending the messages or meanings, now informally explicit, to the top of the spiral loop to construct deeper phenomenal structures of functionality identity itself. Hence, "We know more than we can tell," and all internalize perceived external devices to constantly refresh, review, renegotiate our own self-discoveries (meanings) of comprehension relationships through the "proximal" or "distal" forms [32].

\section{Spatial indwelling of cultural identity}

This spatial recognition of identity is directly connected to social sphere. One, or a group of social connections, can cross into another dimension or paradoxical structures. The knowledge of one's individual identity then becomes a formation of "active shaping's of experience" relative to the special recognition or dimension [32]. This recognition of knowledge, identification of identity, and or group, is found directly connected with a person's current time and space. Dewey contended we shape knowledge from the acts, or actions received in the nature of our experiences in a particular environment. Tacit explanations flow from the observations of the spatial dwelling into conscious "hunches," "findings," and "truths" to enable man to "view a reality with which he is seeking to make contact" [32]. These truths shape "existence," in the cultural realm, "which challenges" one or "others to transform themselves in its image" (p. 80).

The stages of identity adoption are familiar to any process in awareness of a spatial recognition or adoption process. Rogers's (1962) [33] adoption process, although dealing predominantly with adoption of innovations, frames spatial knowledge acceptance in the culture from tacit to explicit knowledge. The tacit knowledge first assimilates the person into the cultural integrations processes. The person becomes aware, or in recognition of, the culture's truths, through hunches, then develop the interests to form observations; which change into evaluations and discoveries. The discoveries of spatial identity knowledge form into explicit knowledge or understandings from the discoveries of truths, which allow for individual's adoption. Ironically, the first stage of Roger's stages of adoption, or awareness, reflects the commonalities associated with tacit knowledge. The awareness stage exposes an individual to knowledge, "but lacks compete information about it" [33]. This is similar to how individuals learning and understands cognitive representations or symbolic understandings in their culture have to formulate and accept interpretations. Perlovsky (2011) [29] states, "primordial origin of language was a unified neural mechanism of fused voicing behavior, emotion motivation, and concept understanding" (p. 2). Social frameworks "incorporate the will" and aim to control intelligence through "guided doings" in a natural order [14]. Participants are meant to "know" and acknowledge perspectives "keying" into actions through cues in brackets of time and space [14]. This creates the disclosure decision model in the sphere where individuals socialize and disclose personal information for 
possible rewards, like in the political matrix. These games of disclosure are impressionistic actions or disclosures identity, and knowledge information to gain spatial recognition in the matrix.

\section{Political indwelling cultural identity}

Gregory Bateson's schismogenic sequences are a root cause of political identity alignment in a culture. The two-fold perspective of symmetrical (the same in reflection) and complimentary (meaning a different behavior), are the prescribed methodologies in identity. The correlation by Bateson (1972)[2] is seen in his three-bit perspective or "Eidos" of a cultural structure to align each individual or identity and behaviors (Ethos). The pragmatic bit is a selfgratification in identity. It causes an individual to align their identity with the accepted cultural politics to satisfy their individual needs. The ethological bit prescribes an emotional connection to the culture's identity, and an expression of equality, while the structural bit teaches the individual to align or partner identity with the whole of the culture or society. This faction is what Bateson proclaims is a systematic scope of patterns and behaviors of identity for an individual to reach "complete fusion" in a politically associated culture.

The acculturation is reflective of Roger's acceptance models by in-group identity. The acculturation requires a period of acceptance, adoption and reaction from the whole. This structural or political alignment or identity in the culture standardizes all personalities, behaviors, and cognitive identity aspects into a unified personality. The schismogenic sequences symmetrically group like identities, and scope their matrix's to align with other complimentary groups in the whole of society itself. These alignments, standardizations of personality, and cognitive identities as Bateson describes, are segregated into four primary layers in the perspective: affective of unity (emotionally inline); economic unity (material object orientation alignment); spatial unity ("behavior is a mechanism orientated toward the production and distribution of material objects"); sociological unity (individual behaviors of identity are orientated towards "integration and disintegration of the major unit"), [2]. Therefore, the individual's identity or ontological actions and concentrations become part of the political party's "transcendental mind" or larger group thought mindset [2].

This mindset has becomes a system described as a "consociates" that all have a unified meaning context or understanding the social sphere [37]. The unification in the political realm becomes clairvoyance to the inter-social being and in essence similar to Bourdieu's theory of social capital. The social capital is based on unified social actions (relations between two people in accordance with group acceptable practices), oriented towards a unified social action [6]. The social actions in the capital are "oriented towards past, present, or future behaviors of another person or persons" for gain [37]. Social actions are oriented towards a party or parties' gains. There are formed "communal actions" "within the sphere or status groups" that form their individual legal order [44]. The actions or planned coordinated communal actions are struggles, aims, or intentions towards the unified coalition's goal [44]. They, the political coalition, have a quasi "eidetic" proposition where the experience or the phenomena of the socialeconomic political group becomes a science of "essential being" that Husserl describes as an established "knowledge of essences (Wesenserkenntnisse) and absolutely free of facts" [17].

\section{CONCLUSIONS}

The philosophical underpinnings of a pure tacit knowledge study is therefore not clearly in place yet [31]. Mackay (1974, p. 94) [19] has argued that "the 'tacit' aspect of knowledge as Polanyi himself has pointed out, is what we have in common with lower animals, presumably all of their 'knowing' is tacit. Therefore, we much distinguish between what we can say we know, and what a suitably equipped observer could say we know; between what we cannot put into words, and what cannot be put into words.

Communication plays an essential role in people's personal and professional lives. Various studies stress the importance of listening as a communication skill. A typical study points out that many of people spend 70 to 80 percent of their waking hours in some form of communication. Communication is a process involving several steps, among two or more persons, for the primary purpose of exchanging information. This process requires sending an idea, receiving the idea, understanding the idea, and providing feedback to the message sender.

An individual's participation in a matrix groups their behavior, expressions, knowledge, and political alignment. The matrix, no matter what the context, is like-minded, and shuns anti-intellectual group thought. This precludes the idea 


\section{Issues in Information Systems \\ Volume 15, Issue I, pp. 248-256, 2014}

that individuals create or manufacture identity or identity knowledge. An individual can take on a role in the matrix relative to the position he or she is ascertaining to establish. This establishment in the dwelling may be nothing more than a fabrication of facts, or a "biographical disguise", whereby the individual is "operating within a particular key or construction, and by virtue of this takes on a part or character- a whole fictive personal identity, not merely a role" [15]. Or, is this the essence of M.C. Escher's paradoxical drawings that consider life a "loop" where we ourselves in identity "not our bodies, but selves- are strange loops, and what we see in ourselves is not fact, not honesty, not "genuine," but an illusion? [16].

This paper sought to describe the context of tacit knowledge exchanges in organizations and contextual problems associated with flow barriers. This research was looked at the structural overview of recent and dated literature; it does propose an extension on its limitations. New research on organizational tacit knowledge flow is needed due to a gap in the literature. Future research should focus on the context of tacit knowledge exchanges in organizations as they relate to the above mentioned communication models and how they relate to the following theories: Diffusion Theory, Agenda Setting Theory, and the Hawthorne Effect to improve upon communication flow barriers. Durbin (2011) [11], expressly points out the limited studies in knowledge management about females in organizations. This paper also suggests that there is a need for the literature to extend into other barriers associated with organizational tacit knowledge exchanges. The table below represents the future research that should be done:

Table 1: Future Research on Tacit Knowledge Exchanges as they relate to Communication Theories

\begin{tabular}{|l|l|}
\hline The Seven C's of Communication & Scott Cutlip and Allen Cetner (1952) \\
\hline Diffusion Theory & E.M. Rogers (1962) \\
\hline Agenda Setting Theory & Maxwell McCombs \& Donald Shaw (1972) \\
\hline Hawthorne Effect & Henry A. Landsberger (1955) \\
\hline The Public Opinion Process & Edward L. Bernays (1928) \\
\hline $\begin{array}{l}\text { Managerial Ties and Firm Innovation: Is Knowledge } \\
\text { Creation a Missing Link? }\end{array}$ & $\begin{array}{l}\text { Shu, Chengli; Page, Albert L; Gao, Shanxing; Jiang, Xu } \\
(2012)\end{array}$ \\
\hline
\end{tabular}

\section{REFERENCES}

1. Collins, B. and Guetzkow, H. (1964). A Social Psychology of Group Processes for Decision-Making (New York:Wiley, 1964), 170-77.

2. Bateson, G. (1972). Steps to an Ecology of Mind: Collected Essays in Anthropology, Psychiatry, Evolution, and Epistemology (1st ed.). University Of Chicago Press.

3. Blau PM, Scott WR (1962) Formal Organizations. Chandler, San Francisco, US

4. Becker, F. (2007). Organizational Ecology and Knowledge Networks. California Management Review, $49(2), 42-61$.

5. Bowman, J., \& Targowski, A. (1987). Modeling the Communication Process: The Map is Not the Territory. Journal of Business Communication, 24(4), 21-34.

6. Bourdieu, Pierre (1986), 'The Forms of Capital', in Richardson, John G., ed., Handbook of Theory and Research for the Sociology of Education, New York: Greenwood

7. Brown, J. S., \& Duguid, P. (2000). The social life of information. Boston: Harvard Business School Press.

8. Castells, Manuel (1996/2000) The information age. economy, society and culture, vol i: the rise of network society. Blackwell Publisher, Oxford

9. Crossan, M., Lane, H. and White, R. (1999), "An organizational learning framework: from intuition to institution", Academy of Management Review, Vol. 24 No. 3, pp. 522-37.

10. Davenport, T., et al (2000). Working Knowledge. Harvard Business Review Press, 1578513014

11. Durbin, S. (2011). Creating Knowledge through Networks: a Gender Perspective: OneSearch. Gender, Work \& Organization, 18(1), 90-112. doi:10.1111/j.1468-0432.2010.00536.x

12. Emery FE, Triest EL (1965) The causal texture of organizational environments. Hum Relat $18: 21-32$

13. Gilbreth FB (1911) Motion study. Van Nostrand, NY

14. Goffman, E. (1986a). Frame Analysis: An Essay on the Organization of Experience. Northeastern.

15. Goffman, E. (1986b). Frame Analysis: An Essay on the Organization of Experience. Northeastern.

16. Hofstadter, D. R. (2008). I am a strange loop. New York: Basic Books 
17. Husserl, E. (2012). Ideas: general introduction to pure phenomenology. London; New York: Routledge

18. Johnson, W. (2007), "Mechanisms of tacit knowing: pattern recognition and synthesis", Journal of Knowledge Management, Vol. 11 No. 4, pp. 123-39.

19. MacKay, D. (1974), "The mechanics of tacit knowing", IEEE Transactions on Systems, Man and Cybernetics, Vol. 4 No. 1, pp. 94-5.

20. March, J. (1991), "Exploration and exploitation in organizational learning", Organization Science, Vol. 2 No. 1, pp. 71-87.

21. Mazzuchi, T., \& Sarkani, S. (2013). Tacit knowledge mobilization effect due to information structure: @RMU Library. Information Knowledge Systems Ma, 12, 115-133. doi:10.3233/IKS-13022

22. Mulder, U. and Whiteley, A. (2007), "Emerging and capturing tacit knowledge: a methodology for a bounded environment", Journal of Knowledge Management, Vol. 11 No. 1, pp. 68-83.

23. Nonaka, I. (1994). A dynamic theory of organizational knowledge creation. Organizational Science. Vol 5. No. 1, pp. 14-37

24. Nonaka, I., \& Takeuchi, H. (1995). The knowledge-creating company: how Japanese companies create the dynamics of innovation. New York: Oxford University Press.

25. Nonaka, I. and Konno, N. (2000). The Concept of "ba;" Building a Foundation for Knowledge Creation. California Management Review. Vol. 40, No. 3, pp. 40-54.

26. Pang, L. (2001). Understand Virtual Organizations. Information Systems Control Journal, 17. Retrieved April 7, 2014 from Research Library ProQuest database.

27. Pascale R, \& Athos, V. (1981) The art of Japanese management. Warner Books, NY

28. Parsons, T. (1951) The social system. Free Press, NY

29. Perlovsky, L. (2011). Language, Emotions, and Cultures: Emotional Sapir-Whorf Hypothesis.

30. Polanyi, M. (1966). The Tacit Dimension. The University of Chicago Press, Ltd., London

31. Polanyi, M. (1967), The Tacit Dimension, Routledge and Kegan Paul, London.

32. Polanyi, M., \& Sen, A. (2009). The tacit dimension. Chicago; London: University of Chicago Press.

33. Rogers, E. M. (1962). Diffusion of innovations. Free Press of Glencoe.

34. Sayle M (1982) The yellow peril and the read haired devils. Harper's November:23-35

35. Smith, E.A. (2001), "The role of tacit and explicit knowledge in the workplace", Journal of Knowledge Management, Vol. 5 No. 4, pp. 311-21.

36. Schramm, W. (1955), "How Communications Works," in The Process and Effects of Mass Communications, ed. Wilbur Schramm (Urbana, Ill.: University of Illinois Press, 1955).

37. Schutz, A. (1972). The phenomenology of the social world. Evanston, Ill.: Northwestern University Press.

38. Shelby, I. K. S. M. 12 (2013) 115-133 115 D. 10. 3233/IK.-130220 I. P. T. knowledge mobilization effect due to information structure

39. Smircich L (1983) 'Leadership': the management of meaning. J Appl Behav Stud18:257-273

40. Stacey, R. (2001). Complex responsive processes in organizations: Learning and knowledge creation. New York: Routledge

41. Taylor, F.W. (1911) Principles of scientific management. Harper \& Row, NY

42. Thomas, D., \& Brown, J. S. (2011). A New Culture of Learning: Cultivating the Imagination for a World of Constant Change. CreateSpace Independent Publishing Platform.

43. Toom, A. (2012). Considering the Artistry and Epistemology of Tacit Knowledge and Knowing. Educational Theory, 62(6), 621-640. doi:10.1111/12001.

44. Venkitachalam, K., \& Busch, P. (2012). Tacit knowledge: Review and possible research directions. Journal of Knowledge Management, 16(2), 357-372. doi:http://dx.doi.org/10.1108/13673271211218915

45. Weber, M., \& Gerth, H. (1981). From Max Weber essays in sociology. New York: Oxford Univ. Press.

46. Zimmerman F. (1997) Structural and management aspects of virtual enterprises. Proceedings of the euro conference on virtual enterprises and network solutions -new perspectives on management communication and information technology. Paderbon, Germany, 7-10 April 1997 